\title{
Distribution of UVC-induced chromosome aberrations along the X chromosome of TCR deficient and proficient Chinese hamster cell lines
}

\author{
W. Martínez-López ${ }^{\mathrm{a}, \mathrm{b}, *}$, E. Marotta ${ }^{\mathrm{b}}$, M.V. Di Tomaso ${ }^{\mathrm{a}, \mathrm{c}}$, L. Méndez-Acuña ${ }^{\mathrm{a}}$, F. Palitti ${ }^{\mathrm{b}}$ \\ a Epigenetics and Genomic Instability Laboratory, Instituto de Investigaciones Biológicas Clemente Estable, Montevideo, Uruguay \\ b Department of Agrobiology and Agrochemistry, Università degli Studi della Tuscia, Viterbo, Italy \\ c Genetics Department, Instituto de Investigaciones Biológicas Clemente Estable, Montevideo, Uruguay
}

\section{A R T I C L E I N F O}

\section{Article history:}

Received 9 February 2010

Accepted 10 February 2010

Available online 20 February 2010

\section{Keywords:}

UVC

NER

Cockayne's syndrome B

Chromosome breakpoints

S-phase BrdUrd labeling

\begin{abstract}
A B S T R A C T
Cells with a transcription coupled repair (TCR) deficiency are characterized by a higher sensitivity to UVC irradiation and by an increase in apoptosis and chromosomal aberration frequencies. It has been claimed that the higher frequency of chromosomal aberrations results from the transcription blockage caused by UVC-lesions located in the transcribed strands of the genome. The distribution of chromosome breakpoints in euchromatic and heterochromatic regions of the X chromosome from TCR deficient and proficient Chinese hamster cell lines was studied. Most UVC-induced breakpoints occurred in euchromatic regions of the X chromosome in both cell lines. No increase of UVC-induced breakpoints in the euchromatic region of the UV61 X chromosome was observed, indicating that TCR failure alone cannot be responsible for the increased frequency of chromosomal aberrations. Differential chromatin remodeling in the TCR defective cell line is proposed as a possible mechanism involved in the distribution of UVC-induced breakpoints along the Chinese hamster X chromosome. A similar explanation for the increase of UVC-induced chromosomal aberrations in TCR defective cells is given.
\end{abstract}

(c) 2010 Elsevier B.V. All rights reserved.

\section{Introduction}

Cyclobutane pyrimidine dimers (CPDs) and pyrimidinepyrimidone 6-4 photoproducts (6-4PP) are the main lesions induced by UVC. About $80 \%$ of the total DNA damage are CPDs [1]. Nucleotide excision repair (NER) is one of the major cellular pathways that remove bulky lesions induced by UVC. Such lesions, if either unrepaired or misrepaired, interfere with essential DNA metabolic activities resulting in mutations, chromosomal instability and cell death [2].

Xeroderma pigmentosum (XP) and Cockayne syndrome (CS) show the dramatic consequences of NER deficiencies. Patients with these syndromes are extremely photosensitive and exhibit skeletal as well as neurological abnormalities. CS gene products are components of the transcription coupled repair (TCR) subpathway of NER which is responsible for removing UVC-lesions from the transcribed regions of the genome [3].

CS cells exhibit elevated frequencies of chromosomal aberrations and an enhanced apoptotic potential after UVC irradiation [4]. Since actively transcribing genes constitute only $5-8 \%$ of the

\footnotetext{
* Corresponding author at: Epigenetics and Genomic Instability Laboratory, Instituto de Investigaciones Biológicas Clemente Estable, Avenida Italia 3318, CP 11.600, Montevideo, Uruguay. Tel.: +5982 4871621 136; fax: +598 24875548 .

E-mail address: wlopez@iibce.edu.uy (W. Martínez-López).
}

eukaryotic genome, lesions repaired by TCR in these regions might be minimal as compared to the remainder of the genome and therefore only a slight increase in apoptosis and chromosomal aberrations in TCR defective cells as compared to normal cells can be expected. Nevertheless, significant increase (3-5 folds) in the induction of both chromosomal aberrations and apoptosis was observed in CS cells upon UVC irradiation [5,6].

AA8 and UV61 are isogenic Chinese hamster cell lines which differ in TCR efficiency. AA8 is the parental cell line, which is proficient in the repair of UVC-induced lesions from the transcribing strand of active genes. UV61 cells (the hamster homologue of human Cockayne syndrome B) originally isolated from AA8 proficiently repair 6-4 PP but are deficient in CPDs removal by the TCR pathway.

As TCR of CPDs is the only difference between AA8 and UV61 cell lines, it can be assumed that the increased level of chromosomal aberrations is mainly due to the lack of CPDs removal from the transcribing strand of active genes. Misrepaired CPDs are thought to be responsible for the formation of chromosomal aberrations during S-phase of the cell cycle. Therefore, it is expected that euchromatic chromosome regions of UV61 should be hot spots for the formation of chromosomal aberrations.

Chinese hamster $\mathrm{X}$ chromosomes have a short euchromatic arm and an almost entirely heterochromatic long arm, which can be easily identify by substitution with 5-bromo-2'-deoxyuridine (BrdUrd) incorporation and indirect anti-BrdUrd immunolabelling during S- 